\title{
PELATIHAN FARM RECORD DAN EVALUASI RESIKO USAHA TANI UNTUK PENINGKATAN KOMPETENSI PETANI MANDIRI
}

\author{
Nurliza*1, Eva Dolorosa $^{2}$, Dewi Kurniati ${ }^{3}$, Joshua Hutajulu $\mathbf{H}^{4}$ \\ ${ }^{1,2,3,4}$ Program Studi Agribisnis, Fakultas Pertanian, Universitas Tanjungpura \\ e-mail: nurliza.spmm@gmail.com
}

\begin{abstract}
The focus of PKM is the "Sumber Lestari" farmer group in Rasau Jaya Village, which is a transmigration area as the Integrated Integrated Zone. Still, farmers in farmer groups do not have farm record so that the difficulty in managing and making optimal farming decisions. This condition is caused by low performance of farmers' skills and risk of farming competencies. Furthermore, farmer groups are only intuitively emphasizing the cost of agricultural production inputs for the most effective farming decisions because of the absence of farm records. Therefore, PKM is tried to give knowledge and training of farm record and farming risk evaluation to achieve the optimal of farming management. The results are shown that the effectiveness ratio is quite effective so that there is still a gap between knowledge and skills that must be followed by the role of local government through continuous monitoring and guidance on the development of processed products to increase the income of surrounding farmers
\end{abstract}

Keywords - Farm record; risk; competence

\begin{abstract}
Abstrak
Fokus kegiatan PKM adalah kelompok tani "Sumber Lestari" di Desa Rasau Jaya, yang merupakan wilayah transmigrasi sebagai pencanangan menjadi Kawasan Terpadu Mandiri/KTM. Namun, petani dalam kelompok tani tidak melakukan pencatatan data usahatani sehingga menyulitkan dalam pengelolaan dan pengambilan keputusan yang optimal. Kondisi ini berdampak pada rendahnya kinerja keterampilan dan kompetensi petani dan diperparah dengan pemahaman aspek manajemen dan pembiayaan usahatani untuk menentukan resiko usahatani yang juga rendah. Selanjutnya, petani dalam kelompok tani hanya secara intuitif menekankan pada aspek biaya dan penerimaan usahatani untuk tujuan pembiayaan input produksi saja dan tidak mampu membuat keputusan usahatani yang optimal. Kondisi ini dilatarbelakangi oleh tidak adanya data usahatani (farm record).Oleh sebab itu, pelatihan farm record dan evaluasi resiko usahatani untuk memberikan pengetahuan dan keterampilan bagi peningkatan kompetensi petani yang mandiri melalui pelatihan farm record dan aspek pembiayaan serta resiko usahatani untuk mencapai kemandirian dan keputusan pengelolaan usahatani yang opimal. Hasil pelatihan menunjukkan rasio efektifitas cukup efektif sehingga masih ada gap antara pengetahuan dan keterampilan yang harus ditindaklanjuti dengan peran pemerintah daerah melalui pemantauan dan pembinaan secara berkelanjutan serta merinti pengembangan pemasaran produk olahan sehingga mampu meningkatkan pendapatan masyarakat kelompok tani sekitar.
\end{abstract}

Kata kunci-Pencatatan usahatani, risiko, kompetensi

\section{PENDAHULUAN}

Fokus kegiatan PKM adalah kelompok tani "Sumber Lestari” di Desa Rasau Jaya, yang merupakan wilayah transmigrasi sebagai pencanangan Kawasan Terpadu Mandiri/KTM atau pusat pertumbuhan baru kegiatan usaha tani untuk mendukung ketahanan nasional, mendorong strategi pemerataan investasi serta menggerakkan pertumbuhan ekonomi rakyat secara berkelanjutan serta daerah fokus pengabdian sesuai kemenristekdikti berdasarkan masukan dari Bappenas. 
Namun, pengelolaan usahatani oleh kelompok tani di Rasau Jaya, Kalimantan Barat khususnya kelompok tani "Sumber Lestari" menunjukkan kinerja keterampilan manajerial petani yang masih sangat rendah yang dibuktikan dengan sebagian besar capaian efisiensi teknis hanya sebesar 60-70\%. ${ }^{[1]}$ Disamping itu, petani dalam kelompok tani umumnya hanya secara intuitif menekankan pada aspek biaya dan penerimaan usahatani untuk tujuan pembiayaan input produksi dan tidak mampu membuat keputusan usahatani yang optimal. Kondisi ini dilatarbelakangi oleh tidak adanya data usahatani (farm record). Disamping itu, petani juga menghadapi kendala internal seperti motivasi, pengalaman usahatani dan luas lahan garapan, pendidikan, karakateristik manajerial serta faktor eksternal seperti sarana dan prasarana. ${ }^{[1][2][3]}$

Kondisi ini dilatarbelakangi oleh tingkat pemahaman petani terkait aspek manajemen pembiayaan dan resiko usahatani yang juga rendah. Hal tersebut diperkuat dengan adanya temuan bahwa sebagian besar penguasaan lahan oleh sebagian besar petani dalam kelompok tani adalah 0,25-1,25 ha dan hanya sebagian kecil yang lebih dari 2,25 ha. ${ }^{[1]}$ Hal tersebut mengindikasikan adanya korelasi positif antara penguasaan lahan, produktivitas, dan pendapatan petani. Disamping itu, tingkat risiko produksi, harga, dan pendapatan usahatani oleh kelompok tani di Rasau Jaya pada beberapa usahatani juga rendah sehingga petani masih dapat memperoleh keuntungan meskipun produktivitasnya tidak terlalu tinggi. ${ }^{[1]}$

Oleh sebab itu, upaya pelatihan farm record dan evaluasi resiko usahatani untuk peningkatan kompetensi petani yang mandiri melalui kelompok tani sangat diperlukan tidak hanya untuk mempromosikan penerapan metode penjadwalan pertanian, tetapi juga merombak rancangan dan sistem usahatani serta meningkatkan keterampilan petani dalam mengendalikan dan mengelola operasional usahatani secara lebih efisien. ${ }^{[4]}$ Disamping itu, intensitas dan interaksi kerjasama dan hubungan sosial antar sesama anggota kelompok ternyata dapat mempengaruhi peningkatan pendapatan usahatani dan mengembangkan kapasitas inovatif. ${ }^{[5]}$ Selanjutnya, hal tersebut juga memungkinkan petani untuk membandingkan keterampilan usahtani, memahami berbagai dampak dari praktik usahatani yang telah dilakukan dan menyesuaikan praktik usahatani tersebut dari waktu ke waktu sehingga dapat memitigasi dampaknya. ${ }^{[6]}$ Dengan demikian, PKM dapat memberikan dan meningkatkan pengetahuan dan keterampilan kompetensi soft-skill dan hard-skill (praktek) sehingga petani menjadi mandiri secara ekonomi dan sosial dan memberikan kontribusi bagi pembangunan pedesaan.

\section{METODE}

Metode pelaksanaan pelatihan farm record dan evaluasi risiko usahatani oleh petani mempertimbangkan keseimbangan tiga aspek penting dalam kegiatan usahatani, yaitu apa yang telah dilakukan, bagaimana hal tersebut dilakukan, dan keterampilan apa yang diperlukan agar tidak terjadi ekses terhadap kreativitas, kinerja, dan perilaku fungsional petani ${ }^{[7]}$. Oleh karena itu, pembuatan farm record menjadi dasar untuk manajemen dan pembiayaan usahtani serta analisis resiko untuk meningkatkan kompetensi petani menuju kemandirian dengan lima tahapan sebagai berikut.

Pertama, penyuluhan dan ceramah pengetahuan dan keterampilan pembuatan farm record. Sasarannya adalah adanya kemampuan petani membuat farm record. 


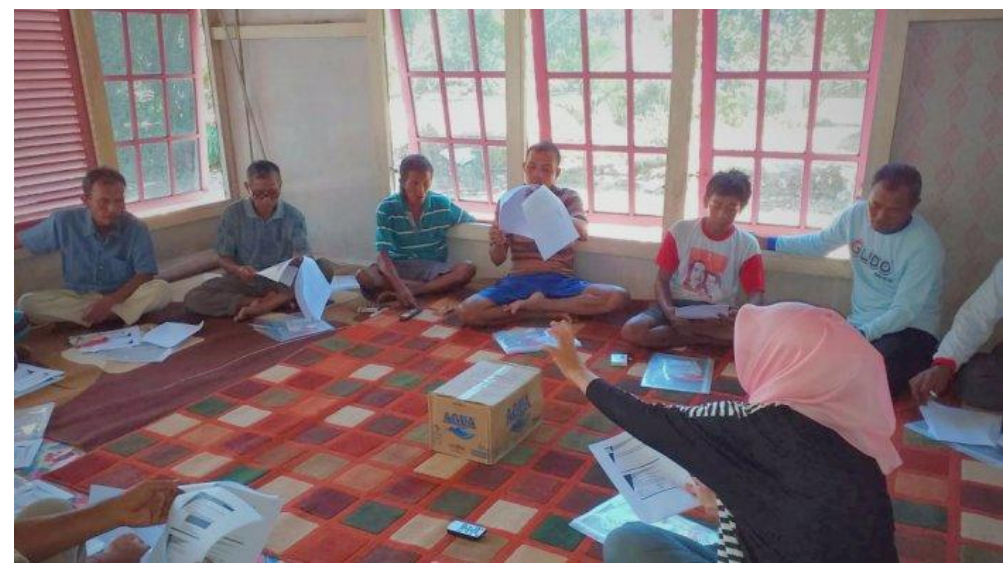

Gambar 1. Pelatihan Farm Record

Kedua, penyuluhan dan ceramah pengetahuan dan keterampilan petani meliputi: aspek teknis produksi, manajemen usahatani, dan pembiayaan usahatani. ${ }^{[8]}$ Sasarannya adalah peningkatan pemahaman petani terkait aspek aspek teknis produksi, manajemen usahatani dan pembiayaan usahatani.

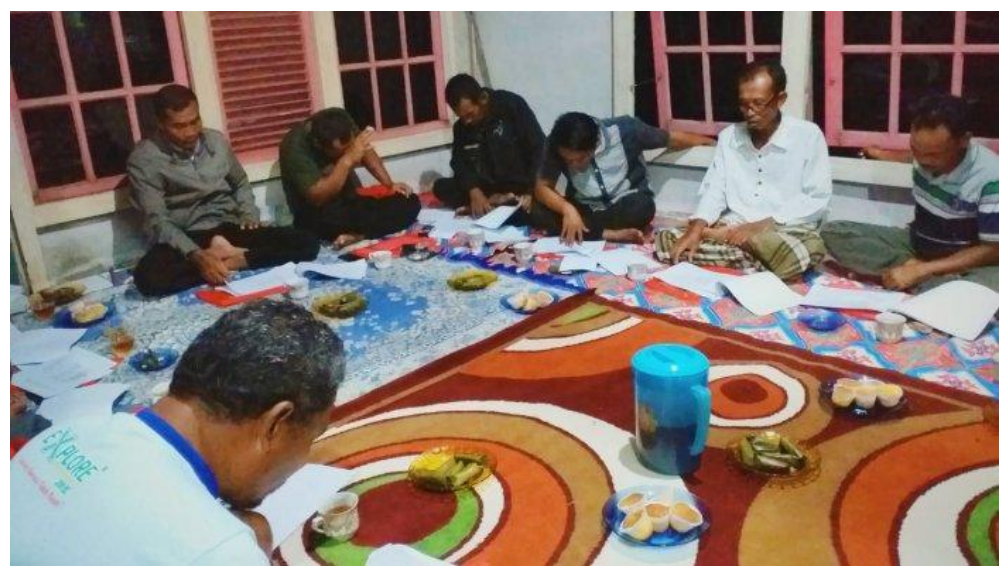

Gambar 2. Pelatihan Aspek Teknis Produksi, Manajemen Usahatani dan Pembiayaan Usahatani

Ketiga, melakukan pencatatan data usahatani (farm record) dan pembiayaan usahatani untuk evaluasi risiko usahatani. Sasarannya adalah petani memahami risiko, membuat keputusan yang lebih baik, dan membuat skenario mitigasi risiko. Pengkajian risiko juga mengarah pada perencanaan yang akurat untuk setiap tingkat risiko agar usahatani lebih menguntungkan.

\section{HASIL DAN PEMBAHASAN}

Hasil pelatihan terhadap kelompok tani "sumber Lestari" menunjukkan rasio efektifitas peningkatan pengetahuan sebesar 100 persen tetapi peningkatan keterampilan sebesar 60-79,99 persen (cukup efektif). Pelatihan pengetahuan yang diberikan kepada petani sebagai berikut:

- Elemen arus kas terdiri dari arus kas dari kegiatan usahatani (operating activities), yaitu kegiatan usahatani baik pemasukan atau pengeluaran; arus kas dari kegiatan investasi (investing activity), yaitu kegiatan penjualan dan pembelian piutang usahatani/ pemasukan dan pengeluaran investasi; dan arus kas dari kegiatan pendanaan (financing activities), yaitu asal pendanaan yang diperoleh untuk usahatani.

- Metode arus kas terdiri dari metode langsung dan metode tidak langsung.

- Ukuran keberlanjutan usahatani dilihat dari: (i) Tingkat Pengeluaran Tidak Melebihi Pemasukan, keuntungan dan pengeluaran per periode seimbang; (ii) Mempunyai Dana Cadangan untuk usahatani beroperasi jika terjadi hal-hal di luar rencana; (iii) Pertumbuhan Positif Saldo Uang Tunai, membagi keuntungan perusahaan untuk diinvestasikan sedikit ke 
dalam usahatani dan sisanya digunakan untuk mengisi dana cadangan; (iv) Tingkat Rasio Utang Cenderung Rendah, usahatani yang sehat memiliki tingkat rasio utang rendah, debt-to-asset, pada kondisi maksimal 1:2.

- Evaluasi kinerja menyangkut rasio ekuitas, total asset turnover ratio, farm to non-farm receipts ratio, rasio likuiditas, rasio layanan hutang/debt service ratio, rasio pembayaran usahatani, pengembalian tingkat hutang dari laba, ROE, dan Total Gross Margin.

- Analisis risiko mencakup risiko produksi, yaitu varibialitas hasil produksi yang tinggi atau risiko yang tinggi; risiko harga /risiko pasar, yaitu varibilitas harga dari pasar pasar endogen maupun eksogen akibat kondisi permintaaan aupun penawaran; risiko keuangan/kredit, yaitu arus kas yang diperburuk juga dengan kurangnya akses petani ke layanan kredit, layanan asuransi dan tingginya biaya pinjaman, proses berbelit dan dipersulit; risiko kelembagaan, yaitu perubahan peraturan, jasa keuangan, tingkat pembayaran dukungan harga atau pendapatan dan subsidi; risiko teknologi, yaitu adopsi teknologi baru dalam modernisasi pertanian seperti pengenalan tanaman transgenik; risiko personal, yaitu risiko aset dari banjir, kekeringan dan kemungkinan kerusakan atau pencurian aset produksi dan aset pertanian lainnya.

- Indikator manajemen risiko adalah Persentase Kenaikan Biaya Bahan Baku; Persentase Kenaikan Harga Pokok Penjualan; Persentase Kenaikan Upah; Persentase Kapasitas Produksi yang Menganggur; Persentase Nilai Investasi Kapasitas yang Menganggur.

- Jenis-jenis pengukuran risiko sebagai berikut.

Tabel 1. Jenis-Jenis Pengukuran Risiko Usahatani

\begin{tabular}{|c|c|c|}
\hline Tipe risiko & Definisi & Teknik pengukuran \\
\hline Resiko Produksi & $\begin{array}{l}\text { Benih, Pupuk, Pestisida, tenaga kerja } \\
\text { dan Peralatan }\end{array}$ & Koefisien Variasi (CV) \\
\hline Risiko pasar & $\begin{array}{l}\text { Harga jual di pasar tidak } \\
\text { menguntungkan (merugikan) }\end{array}$ & $\begin{array}{l}\text { Value at Risk (VaR), } \\
\text { stresstesting }\end{array}$ \\
\hline Risiko kredit & $\begin{array}{l}\text { Tidak mampu membayar } \\
\text { kewajiban/hutang tingkat bunga } \\
\text { berubah }\end{array}$ & $\begin{array}{l}\text { Credit rating, credit } \\
\text { metrics, Metode } \\
\text { pengukuran jangka } \\
\text { waktu,durasi }\end{array}$ \\
\hline Risiko operasional & Kegagalan operasional & $\begin{array}{l}\text { Matriks frekuensi dan } \\
\text { signifikansi kerugian, } \\
\text { VaR Operasional }\end{array}$ \\
\hline
\end{tabular}

- Mitigasi risiko sebagai berikut: (i) Risk Assumption, yaitu menerima risiko potensial dan terus mengoperasikan system atau yang dapat diterima; (ii) Risk Advoidance, yaitu menghindari risiko dengan menghilangkan penyebaab risiko dan/atau konsekuensi; (iii) Risk Limitation, yaitu membatasi risiko dengan control yang meminimalkan dampak merugikan dari ancaman; (iv) Risk Planning, yaitu mengelola risiko dengan membangun suatu rencana mitigasi yang memprioritaskan, menerapkan, dan memelihara control; (v) Research and Acknowledgment, yaitu mengurangi risiko kerugian dengan menyadari kelemahan atau cacat dan meneliti sebuah control untuk memperbaiki kerentanan; (vi) Risk Transference, yaitu transfer risiko dengan menggunakan pilihan lain/ketiga untuk mengganti kerugian, seperti pembelian asuransi.

Keseriusan dan kemauan untuk memperoleh informasi terkait aspek produksi juga merupakan kunci usahatani yang berkelanjutan. Salah satu aspek teknis produksi dalam pelatihan adalah membangun kemandirian masyarakat dalam pengelolaan lahan gambut sebagai berikut:

- Tingkat kematangan gambut dibedakan menjadi: (i) Gambut saprik (matang) adalah gambut yang sudah melapuk lanjut dan bahan asalnya tidak dikenali, berwarna coklat tua sampai hitam, dan bila diremas kandungan seratnya kurang dari 15\%; dan (ii) Gambut hemik (setengah matang) adalah gambut setengah lapuk, sebagian bahan asalnya masih bisa dikenali, berwarma coklat, dan bila diremas bahan seratnya $15-75 \%$ : (iii) Gambut fibrik (mentah) adalah gambut 
yang belum melapuk, bahan asalnya masih bisa dikenali, berwarna coklat, dan bila diremas $>75 \%$ seratnya masih tersisa.

- Kedalaman gambut dibedakan menjadi: (i) Gambut dangkal $(50-100 \mathrm{~cm})$; (ii) Gambut sedang $(100-200 \mathrm{~cm})$; (iii) Gambut dalam $(200-300 \mathrm{~cm})$; (iv) Gambut sangat dalam (lebih dari 300 $\mathrm{cm})$

- Langkah-langkah menjadikan gambut sebagai lahan produktif sebagai berikut: (i) Budidaya tanaman hanya di lahan gambut dengan kedalaman kurang dari $3 \mathrm{~m}$; (ii) Tidak menggunakan lahan gambut yang membentang di atas lapisan pasir dan tidak menggunakan lahan yang letak lapisan piritnya dangkal kecuali ada jaminan irigasi sepanjang tahun; (iii) Tidak melakukan penyiapan lahan dengan cara bakar; (iv) Penataan lahan dan pemilihan jenis/varietas tanaman sesuai; (v) Mengolah tanah dengan minimum tillage (olah tanah minimum); (vi) Ditanami ubikayu untuk mempercepat kematangan gambut; (vii) Menggunakan ameliorant; (viii) Pembangunan jaringan drainase harus disertai dengan pembangunan jaringan irigasi dan pintupintu (sekat kanal) yang dapat menjamin keberadaan air

- Pembukaan lahan tanpa bakar (PLTB) sebagai berikut: (i) Perencanaan Penanaman; (ii) Membuat Rintisan dan Pembagian Petak Tanaman; (iii) Mengimas (Penebasan semak dan pohon kayu dengan menggunakan parang atau kapak); (iv) Merencek (pencincangan); (v) Membuat Pancang Jalur Tanam/Pancang Kepala; (vi) Membersihkan Jalur Tanam.

berikut:

Selanjutnya, aspek teknis produksi dalam pelatihan adalah budidaya tanaman sebagai

- Menggunakan benih unggul/benih yang mempunyai potensi hasil dan kualitas yang tinggi, bahan tanaman disimpan dengan baik, agar tidak mudah rusak, melakukan seleksi dengan pemilihan benih dan penanaman, perlakuan benih membebaskan benih dari hama dan penyakit atau performa benih

- Persiapan lahan yang mencakup: (i) Terciptanya struktur tanah yang dibutuhkan untuk tempat tumbuh tanaman; (ii) Tanah yang padat diolah sampai menjadi gembur sehingga mempercepat infiltrasi air, berkemampuan baik menahan curah hujan memperbaiki aerasi dan memudahkan perkembangan akar; (iii) Menghambat atau mengendalikan tumbuhan pengganggu; (iv) Membenamkan tumbuhan-tumbuhan atau sampah-sampah yang ada di atas tanah kedalam tanah, sehingga menambah kesuburan tanah; (v) Mengendalikan serangga, larva, atau telur-telur serangga melalui perubahan tempat tinggal dan terik matahari.

- Penanaman mencakup: (i) Penanaman di lapangan dapat dilakukan dengan dua cara, yaitu: (i) langsung menanam benih di lapangan dan menanam bibit di lapangan; (ii) Kedalaman tanam dengan memperhatikan tipe perkecambahan, ukuran benih, kandungan $\mathrm{O}^{2}$ dan $\mathrm{CO}^{2}$ dalam tanah, dan kerapatan tanam (jarak tanam).

- Pemeliharaan yang mencakup: penyulaman, penyiraman, pembubunan, pemupukan, pengendalian hama dan penyakit, dan pengendalian Gulma.

- Panen dengan memperhatikan waktu panen tergantung jenis tanaman dan bagian tanaman (akar, batang, daun, bunga dan buah) yang akan dipanen; kriteria panen; dan hasil panen yang baik, bukan hanya jumlah (kuantitas) yang tinggi, tapi juga mutu (kualitas) yang tinggi.

- Usahatani jahe yang dilakukan oleh petani harus memperhatikan mutu standar perdagangan rimpang jahe segar sebagai berikut: (i) Mutu I, bobot $250 \mathrm{~g} /$ rimpang, kulitnya tidak terkelupas, tidak mengandung benda asing dan kapang; (ii) Mutu II, bobot 150-249 g/rimpang, kulitnya tidak terkelupas, tidak mengandung benda asing dan kapang; (iii) Mutu III, bobot sesuai hasil analisis, kulit yang terkelupas maksimum $10 \%$, benda asing maksimum $3 \%$, dan kapang maksimum $10 \%$.

Namun, pemasaran produk juga menjadi faktor yang sangat menentukan keberlanjutan usaha yang tentu saja sangat membutuhkan dukungan dan peran serta pemerintah daerah khsususnya untuk dapat membina dan meningkatkan kemampuan kelompok tani tersebut agar dapat bertahan dan bersaing dengan produk sejenis dari usaha lainnya. Upaya promosi oleh pemerintah daerah dapat menjadi salah satu upaya untuk meningkatkan pemasaran produk baik melalui pameran maupun kegiatan lainnya sehingga semakin dikenal dan disadari keberadaannya oleh masyarakat luas, menarik minat dan menimbulkan keinginan masyarakat untuk membelinya. 


\section{KESIMPULAN}

Kesimpulan PKM antara lain: (i) Pemberdayaan kelompok tani dapat berkembang jika difasilitasi dan didukung eksistensinya oleh masyarakat dan pemerintah daerah setempat; (ii) Sosialisasi dan pelatihan pengetahuan dan keterampilan farm recod dan evaluasi risiko usahatani sebagai informasi sangat diperlukan bagi pemberdayaan masyarakat kelompok tani sekitar; (iii) Keberadaan produk olahan jagung dan jahe yang aman dan higienis dapat dijadikan perintis untuk pengembangan produk dan pemasaran lebih lanjut sehingga mampu meningkatkan pendapatan masyarakat kelompok tani sekitar.

\section{SARAN}

Adanyagap antara pengetahuan dan keterampilan yang harus ditindaklanjuti dengan peran pemerintah daerah melalui pemantauan dan pembinaan secara berkelanjutan terutama terkait aspek teknis dan pembiayaan usahatani serta merintis pengembangan pemasaran produk olahan sehingga mampu meningkatkan pendapatan masyarakat kelompok tani sekitar.

\section{UCAPAN TERIMA KASIH}

Tim penulis mengucapkan terima kasih kepada Fakultas Pertanian UNTAN melalui Skema dana DIPA Universitas Tanjungpura sesuai Surat Perjanjian Pelaksanaan Penelitian Nomor: 98/UN22.3/PP/2019, tanggal 8 April 2019 yang telah memberi dukungan keuangan terhadap kegiatan PKM ini.

\section{DAFTAR PUSTAKA}

[1] Nurliza, Dolorosa, E., \& Yusra, A. H. (2017). Rice Farming Performance for Sustainable Agriculture and Food Security in West Kalimantan. AGRARIS: Journal of Agribusiness and Rural Development Research, 3(2), 84-92.

[2] Rukka, H., Buhaerah, \& Sunaryo. (2006). Hubungan karakteristik petani dengan respon petani terhadap penggunaan pupuk organik pada padi sawah (Oryza sativa L). Jurnal Agrisistem, 2(1), 23-31.

[3] Wilson, P., Hadley, D., Ramsde, S., \& Kaltsas, I. (1998). Measuring and explaining tehnical efficiency in UK potato production. Journal of Agricultural Economics, 49, 294-305.

[4] May, Z., \& Amran, M. H. (2011). Automated oil palm fruit grading system using artificial intelligence. International journal of video \& image processing and network security 11(3).

[5] Irawati, E., \& Yantu, M. R. (2016). Kinerja Kelompok Tani dalam Menunjang Pendapatan usahatani Padi Sawah Di Desa Sidera Kecamatan Sigi Biromaru Kabupaten Sigi. e-J. Agrotekbis 3 (2) , 206-211.

[6] Elferink, E., Kuneman, G., Visser, A., \& van der Wal, E. (2012). Sustainability Performance Assessment of Farming Practices: Guidelines for developers of quantitative monitoring tools. Culemborg, Netherlands: Centre for Agriculture and Environment (CLM).

[7] Billikopf, G. (2014). Labor Management in Agriculture: Cultivating Personal Productivity. California, USA: University of California.

[8] Nooraie, M. (2012). Factors Influencing Strategic Decision-Making Process. International Journal of Academic Research in Business and Social Sciences, 2(7), 405-429.

[9] Khan, M. A., Huda, F. A., \& Alam, A. (2010). Farm Household Technical Efficiency: A Study on Rice Producers in Selected Areas of Jamalpur District in Bangladesh. European Journal of Social Sciences, 14(2)2010, 262-271.

[10] Gultom, L., Winandi, R., \& Jahroh, S. (2014). ANALISIS EFISIENSI TEKNIS USAHATANI PADI SEMI ORGANIK DI KECAMATAN CIGOMBONG, BOGOR. Informatika Pertanian, 23(1), 78. 
[11] Suharyanto, Mulyo, J. H., Darwanto, D. H., \& Widodo, S. (2015). Analisis Produksi dan Efisiensi Pengelolaan Tanaman Terpadu Padi Sawah di Propinsi Bali. Penelitian Tanaman Pertanian Pangan, 34(2), 131-144.

[12] Kumbhakar, S. C., \& Tsionas, E. G. (2006). Estimation of stochastic frontier production functions with input-oriented technical efficiency. Journal of Econometrics, 133(1), 71-96.

[13] Wilson, J. R., Hashimoto, R. E., Dettori, J. R., \& Fehlings, M. G. (2011). Spinal cord injury and quality of life: a systematic review of outcome measures. Evid Based Spine Care J., 2(1), 37-44.

[14] Kusnadi, N., Tinaprilla, N., Susilowati, S. H., \& Purwoto, A. (2011). Analisis efisiensi usahatani padi di beberapa sentra produksi padi di Indonesia. Jurnal Agro Ekonomi 2(1), $25-$ 48.

[15] Murniati, K., Mulyo, J. H., Irham, \& Hartono, S. (2014). Efisiensi teknis usaha tani padi organik lahan sawah tadah hujan di Kabupaten Tanggamus Provinsi Lampung. Jurnal Penelitian Pertanian Terapan 14 (1), 31-38. 